\begin{tabular}{ccc}
\hline International Journal of Engineering \& Technology, $7(3.2)(2018) 203-208$ \\
SPC & Website: $w$ ww.sciencepubco.com/index.php/IJET \\
Research paper & Technology \\
\hline
\end{tabular}

\title{
Energy Efficiency of a Hydraulically Actuated Plastering Machine
}

\author{
Bogdan Korobko $^{1^{*}}$, Dmytro Zadvorkin ${ }^{2 *}$, Ievgen Vasyliev $^{3}$ \\ ${ }^{I}$ Poltava National Technical Yuri Kondratyuk University, Ukraine \\ ${ }^{2}$ Poltava National Technical Yuri Kondratyuk University, Ukraine \\ ${ }^{3}$ Poltava National Technical Yuri Kondratyuk University, Ukraine \\ *Corresponding Author E-Mail: Bogdan.Korobko@Ukr.Net
}

\begin{abstract}
The supposition of productivity gain of finishing work using plastering machines has been considered in the article. The work of constituent parts of plastering machines has been studied. The working parameters of the plastering machine has also been calculated. There has been evolved the planning of a three-factor experiment of the second order with the aim of determining the working power, consumed by the mortar pump.
\end{abstract}

Keywords: plaster station, solution, hydraulic drive, energy efficiency.

\section{Introduction}

The efficiency improvement of construction is achieved mainly by means of the improvement of the quality of construction and due to the rise in labour productivity, the reduction of construction time and the volume contraction and decrease in the value of manual construction work.

The solution of these tasks to a large extent can be favoured by the increase of labour efficiency in plastering and stuccoing operations, the labour-intensive characteristic of which is $25 \ldots 30 \%$ of all costs both in new construction, as well as in the repair and reconstruction of various objects. At the same time, the most labor-intensive are plastering works, the cost of which reaches $18 \ldots$ $20 \%$ of all expenditures on construction and erection work [1].

Despite the fact that in recent years, in interior finishing of the buildings the constructors and designers commonly began to apply gypsum moulding plaster, the so-termed "wet processes of plastering" have not been reduced significantly.

The peculiarity of the technology and the properties of materials used in finishing $[2,3,4]$, in some cases, do not allow to mechanize production processes and therefore they have to be performed manually. Especially great part of manual labor is observed at geographically scattered objects. Therefore, the question of mechanization of finishing works is of particular importance, since the quality and execution period of their implementation to a large extent influence the timely setting of objects into operation.

Finishing works is a complex of building operations related to the interior and exterior decoration of buildings and structures in order to enhance their protective-exploitation and architectural and aesthetic qualities.

Despite the development of industrial furnishing, plastering remains one of the most common types of finishing works, especially in brick housebuilding, which has recently developed considerably [5]. During plastering works the builders often use finishing mortars of different composition - cement or cement-limestone [6, 7].
Depending on the volume of plaster work on sites, finishing mortars are prepared on permanently operating centralized batching plants or directly on building sites, using mechanized mobile mortar mixing plants [8].

Vehicles with special bodies or dumptrucks with hermetically sealed bodies transport the ready mix mud from the batching plants to the construction sites.

Dynamic shakes of autobodies and gravitational forces violate the homogeneity of solutions and reduce their initial medium workability, so the solution on the construction site must be brought back to the appropriate body $[9,10,11,12,13]$.

The main feature of the mixer of the plastering machine, in contrast to mortar mixing plants and concrete mixing plants, used for industrial manufacture of mortar mixtures, is that, in addition to mixing (usually of the redi-mixes), the mixer in the plastering machine must provide the transfer (delivery) of the solution to the injection tank of the mortar pump.

The specified task can be solved by the development of a plastering machine, the combination of rational geometric characteristics and successful structural solutions of which will allow to ensure the highest possible uniformity of the composition and mobility of the mortar in the entire volume of the mixer as well as to intensify the mixing process provided that there will be the required level of mixture supply to the injection tank of the mortar pump and to reduce energy consumption during the operation of this type of construction machinery.

At present, plastering machines of various designs are used in building organizations of Ukraine. But most of them in one way or another do not meet the requirements for these machines, made by modern technology of applying building mortars. This can be explained by the moral obsolescence of technical solutions used in the manufacture of the specified equipment.

The main disadvantages of existing plastering machines are as follows:

- too high location of the charging door of the receiving hopper, which makes it necessary in the process of acceptance of the mortar from the carbody of the dumptruck to use special, very incon- 
venient at work, racks or ramps, which complicate the process of receiving the mortar;

- insufficient capacity of the receiving hopper (for example, in plastering machines with a Tolmer wheel);

- small tilt angles of the side walls of the receiving hopper, which causes the detention of mortar on them;

- poor possibility to "enliven" the building mortar after a long work-break;

- the absence of warmth-keeping in the hopper-mixer and in the operator's cab;

- imperfection of the devices for filtering of mortars and removal of residual, which reduces the quality of mortars and makes it difficult to maintain the plastering machine.

Also, the significant disadvantage of many plastering machines is the use in their composition of mortar pumps of outmoded structures, that do not provide stable continuously controlled delivery of building mortars of different composition and purpose in a wide range of mobility at sufficient pressure level and low pulsation, are characterized by low level of volume and total efficiency.

The most widely used is the type of equipment, in which the required uniformity of the mortar is achieved by mechanical influence on the environment by a special working body called the mixer. Typically, for the preparation of building mortars, mixers with a working body of mechanical action are used.

It is known that building mortars are mechanical mixtures of solid ingredients of a filler and a binder with water. The basic physical and mechanical properties of mortar mixtures can be characterized by such parameters as density, viscosity and granulometric composition. These indicators have a direct influence on power consumption during mixing. In this regard, agitator mixers have got widespread as concerns mixing of the components.

However, in some cases, some of building mortars are made in concrete mixers, in which mixing is carried out on the principle of "free falling". This fact is not typical for the production technology of building mortars. It is connected with the local conditions of works, in particular with the desire to use one and the same machine to prepare not only concrete, but also mortar.

The most promising plastering machines where the hydraulic drive is used, which allows them to significantly reduce their energy and metal capacity; they are mobile (moved by automobile transport) All equipment is mounted in the metal wagon of the plastering machine, and heating may be provided for the corresponding maintenance throughout the year.

\section{Main Body}

As noted above, many factors affect the process of finishing work, which are related not only to the nature of the stirred and transported mortar, but also to the design of the mixing device, the mortar pump, the method of mixing, etc. A large number of criteria that have to be taken into account when choosing the equipment makes it difficult to choose its type only on the basis of theoretical data.

When developing the technological package, the main attention is paid to its basic aggregates - the mixer and the mortar pump. In our opinion, the most reliable way of choosing the rational design of a set of equipment may be as follows. Based on the study of literary sources and available practical recommendations, taking into account analogies of their own technological preconditions, the type of mixer is initially selected. In this case, the choice of a mixer is determined primarily by the following factors:

1) ensuring the necessary degree of homogeneity of the mortar the main parameter that determines the quality of the product solution. That is why the chosen type of mixer, of course, must guarantee a given degree of homogeneity of the mortar. Obviously, its bringing up to a higher degree of homogeneity increases the net cost of the mixing operation, which must also be taken into account;

2) estimation of the power magnitude, consumed for mixing. Different types of mixers have a very different level of power con- sumption. However, in the case where several types of mixing devices meet all the requirements of a manufacturing operation, a low-power mixer is selected in the light of operating costs;

3 ) mixing time. This parameter should be such that the intensive mixing operation in the plastering machine mixer would not become the "bottleneck" in the technological process of doing the finishing works. Usually, according to the production experience, the time sufficient to bring the ready mix mud to the required conditions is 5-10 minutes. It should also be noted that mixing time depends not only on the type of mixer, but also on the working volume of the housing of the mixing unit.

Having analyzed the considered designs of mortar nodes, one may state that it is logical to assume that the most successful structural solutions are inherent in such devices:

1) the faucet body is rotary; it allows the solution to be placed into the active mixing zone without any particular structural difficulties and to avoid the equipment of the access trestle for unloading of the dump truck;

2) the working body of the mixer - is tape-lobed with the discharge of the mortar from the end face of the mixer.

In this case, it should be noted that it is the tape-blade mixer which will provide the most active movement of the mortar to the injection tank of the mortar pump, which is necessary for the mixer of a plastering machine.

In order to ensure the operation of hydraulic cylinders in widespread designs of plastering machines there have been installed oil pumping facilities, which are switched on only several times per shift for a short time, in other words, are used very inefficiently.

Due to the widespread use of plastering machines, partly equipped with hydraulic drives, the hydraulic mortar pump RNG-4 was engineered and tested, the advantages of which are the reduced pressure fluctuation magnitude of the mortar supply and the possibility of smooth flow control. The successful construction of the pump allowed the development of a fully hydraulic-driven plastering machine $\mathrm{SSH}-4 \mathrm{G}$.

The plastering machine SSH-4G (fig.1) contains frame 1, on which a rotary hopper mixer 2 is mounted with a mechanical stirrer 3 and its actuator 4 . The rotation of the mixer hopper is carried out with the help of two hydraulic cylinders 5. The frame also includes a hydraulically propelled mortar pump of 6 grade RNG-4 with oil pump 7. The wagon 8 with the gate 9 and the door 10 is welded up to the frame.

The front trunnion of the hopper mixer is hydraulically connected to the injection tank 11 and to the mortar pump. In the bottom of the hopper above the injection tank there is a removable grille 12 with stepped holes, which serve for straining the solution, which is delivered into the mortar pump. Along with the grille in the bottom of the bunker there is provided a window with a lid, through which the accumulated sludge should be removed at the end of the shift.

At the front end wall of the wagon in the middle of the cabin, the electricity closet 14 and the table 15 of the distributive valve are fixed to control the operation of the hydraulic cylinders of the rotation of the hopper-mixer.

This particular model of plastering machine best of all meets the modern requirements for the complex mechanized carrying out of works related to the use of building mortars. After all, the plastering machine SSH-4G has the following technological advantages: 1. The height of the loading window of the receiving bunker of the plastering machine ensures the acceptance of the building mortar directly from the carbody of the dump truck of any load carrying capacity without the use of special ramps or trestles. This gives the plastering machine more mobility within the construction site and significantly reduces the time to establish the station in the working position and its operation.

2. The design of the hopper-mixer station provides not only thorough mixing of the mortar and feeding it to the mortar pump, but also the possibility to "induce" the mortar, which partially lost its mobility as a result of a long break in the work of the mechanical stirrer. 
3. The side walls of the mixer hopper plaster station have large angles of slope to the horizon $\left(\sim 70^{\circ}\right.$ in the working position). This is required for the building mortars to flow better down the walls of the bunker. After all, manual cleaning of the walls of the bunker from mortar stone greatly complicates the servicing of plastering machine, and hardened residues of the mortar, which fall into the pumparound mortar, significantly reduce its quality and prevent the performance of plastering.

4. The station is equipped with an effective device for straining the mortar pumped by the mortar pump. The filtration rating is $6 \ldots 8$ $\mathrm{mm}$.

5. The most important advantage of the station SSH-4G is its equipment with hydraulic driven mortar pump RNG-4, which can stably pump up low-slump building mortars at the delivery pressure of not less than $4 \mathrm{MPa}$, smoothly adjusting the feeding within the limits of $1 \ldots 4 \mathrm{~m}^{3} / \mathrm{h}$, with minimal pressure pulsation.

From the above mentioned and generalized analysis of the requirements to the equipment for plastering works, the current state of development of structures implies that the most promising is the design of a pump, capable of providing a low-impulse supply of sluggish building mortars under the pressure of $4-6 \mathrm{MPa}$ with minimum energy and volume losses, based on differential principle of operation, is equipped with flow-through working organ of plunger type with ball valves. The pump drive must provide uniform motion of the working body for most of the cycle.

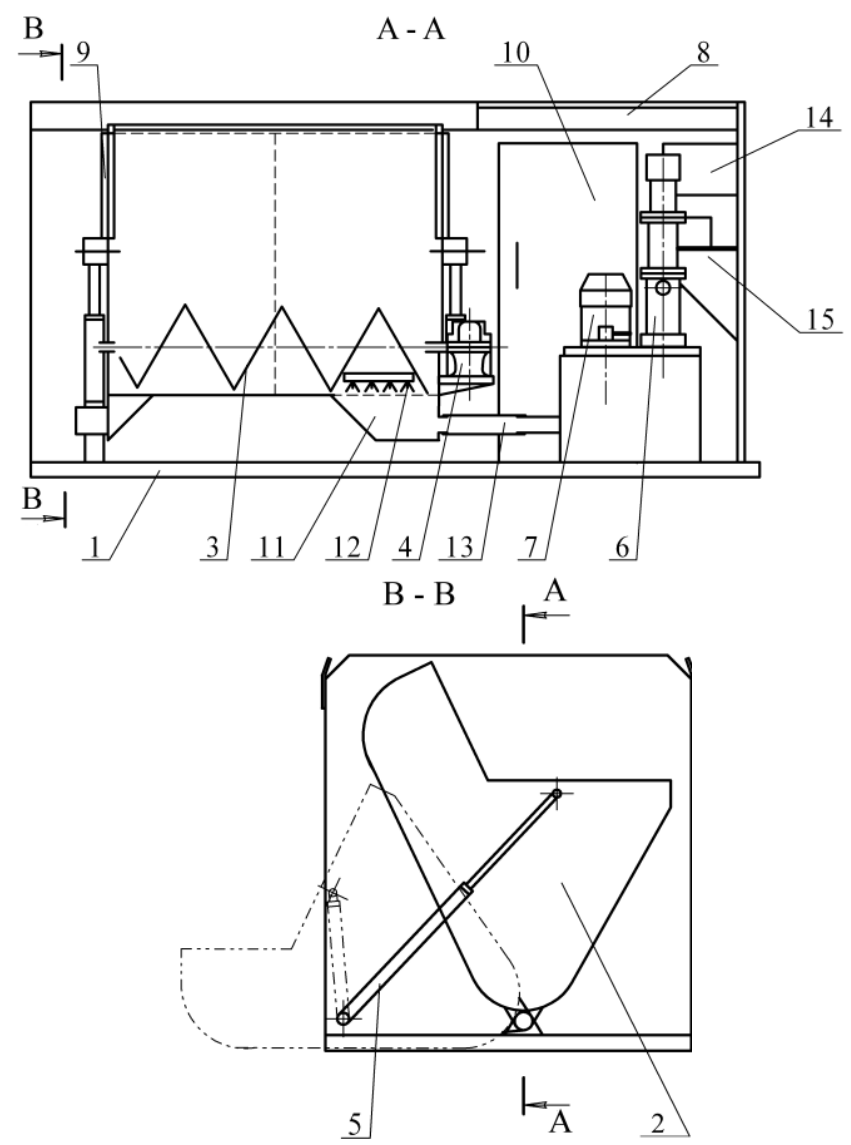

Fig. 1. The schematic structure of the station SSH-4G: 1 - frame; $2-$ mixer hopper; 3 - mixer; 4 - drive of the mixer; 5 - hydraulic cylinder; 6 mortar pump; 7 - oil-pumping station; 8 - wagon; 9 - the gate; 10 - doors; 11 - injection tank; 12 - a filtration grille; 13 - rubberized fabric hose; 14 - electricity closet; 15 - distributive valve

The pump should be of small size and weight, of simple and reliable structure. The implementation of such a construction can be done using the hydraulic drive of the flow-through plunger. In this case, the differential property of the plunger allows to be confined to one working body and to simplify the design of the hydraulic part.
The hydraulic drive is capable of providing the mode of operation in which the fluctuations of supply and pressure will be minimal, and an increased level of efficiency will reduce the energy input consumed by pumping the mortars.

The use of mortar pumps with hydraulic drive allows you to perform the finishing works most effectively, provided that they are used as part of complex hydrophilic plastering machines.

Based on the stated advantages, disadvantages and peculiarities of using the equipment of technological kits and using the mathematical tool, it can be argued that it is possible and necessary to develop scientific approach to the selection of components on the basis of the highest energy efficiency taking into account the specific building conditions and the properties of the working environment (plaster mortar).

The main parameters that determine the energy efficiency of equipment of various standard sizes are the pressure and the flow of the power fluid.

The research results show that at any time during the work of a hydraulic cylinder of a mortar pump in a reciprocating mode and at rotation of a shaft of a fluid-power motor of a working body all differential pressure and hydraulic fluid consumption will be provided with corresponding indicators of a hydraulic pump.

There is a need for research and comparison of the parameters of the hydraulic system operation, which brings into action the working bodies of the mortar pump and the mortar pump of the plastering machine.

At simultaneous operation of a hydraulic motor of a mixer's working body and a hydraulic cylinder of a mortar pump the delivery of oil by a hydraulic pump is:

$Q_{p}=\left(Q_{h m}+Q_{h c}\right) \cdot \eta_{v \cdot p}$.

where $Q_{h m}$ - oil consumption on a hydraulic motor;

$Q_{h c}$ - oil consumption on the mortar pump;

$\eta_{v \cdot p}$ - the volume efficiency of the pump.

The pressure in the hydraulic system $p_{p}$ is provided by a pump which has to be selected by maximum discharge in the system or by installed capacity.

The work of each working member of the plastering machine equipment for the performance of finishing works should first be considered separately: the operating body of the mixer and of the mortar pump.

For working body of the mixer:

Oil consumption on the hydraulic motor $Q_{h m}$

$Q_{h m}=\frac{V_{h m} \cdot n_{h m}}{\eta_{v, h m}}$

where $V_{h m}$ - the volume of the hydraulic motor;

$n_{h m}$ - the frequency of rotation of the hydraulic motor shaft;

$\eta_{v, h m}$ - the volume efficiency of the hydraulic motor.

Since the volume of the hydraulic motor and the rotary velocity are constant, then we take up $Q_{h m}=$ const .

The pressure difference on the hydraulic motor of a mortar mixer is defined as:

$\Delta p=\frac{N_{h m}}{V_{h m} \cdot n_{h m} \cdot u_{r e d} \cdot \eta_{v \cdot h m}}$

where $u_{\text {red }}$ - the gear ratio of the gear unit between the shaft of the hydraulic motor of the mixer drive and the shaft of the working body of the mixer.

The power on the shaft of the fluid-power motor of the mixer, taking into account the overall dimensions of the mixer housing 
and the operating body of the mixer, as well as considering the composition and mobility of the mortar, have been investigated in the research [14], the results of which are shown in Fig. 2.

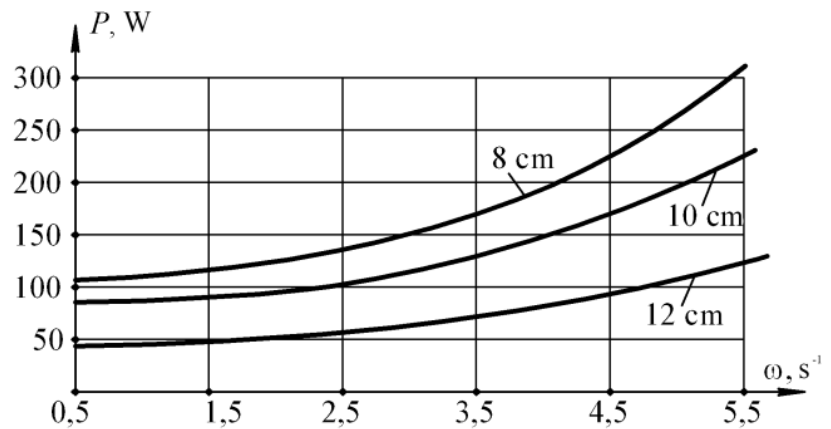

Fig. 2. Theoretical dependence of power consumption of hydraulic drive equipment for finishing work on the angular velocity of the shaft of the mixer's working body for the mortars of various mobility

For our case, it is determined that the pressure change on the hydraulic motor of the operating device of the mixer's drive will depend on the mobility of the mortar and the angular velocity of the shaft of the mixer's working body. For the mortars with the lowability of $8 \mathrm{~cm}$, the differential pressure on the hydraulic motor $\Delta p$ is $1.08 \mathrm{MPa}$ at the oil supply $Q_{p}=0.302 \mathrm{~m}^{3} / \mathrm{h}$

The consumed mortar pump power, $\mathrm{kW}$, in the process of pumping mortars, is determined by the formula [15]

$$
P_{c o n}=\frac{p \cdot Q_{t}}{1000 \cdot \eta_{m p}},
$$

where $p$ - the pressure required for mortar pumping, $\mathrm{Pa} ; Q_{t}-$ the theoretical supply of the mortar pump, $\mathrm{m}^{3} / \mathrm{s} ; \eta_{m p}$ - the total efficiency of the mortar pump

$\eta_{m p}=\eta_{h} \cdot \eta_{v} \cdot \eta_{m}$

where, $\eta_{h}, \eta_{v}, \eta_{m}$ - is the hydraulic, volume and mechanical efficiency of the pump respectively.

Depending on the drive's mode of operation, there is fluctuation of supply and pressure. To a certain extent, this results in changes in the value of hydraulic and volume efficiency and power consumption in general $[16,17]$.

The work of the hydraulic system of the mortar pump's drive should be considered at its various phases - acceleration, constant movement, braking of working bodies (of the hydraulic cylinder piston together with the flow-through piston of the pump column, the control spool and the main spool).

The results of the research, which are shown in Fig. 3 [18], allowed to investigate the full cycle of operation of the mortar pump both in separate phases, and for each phase, to determine their duration, the nature of the change in the level of oil pressure in the pressure line.

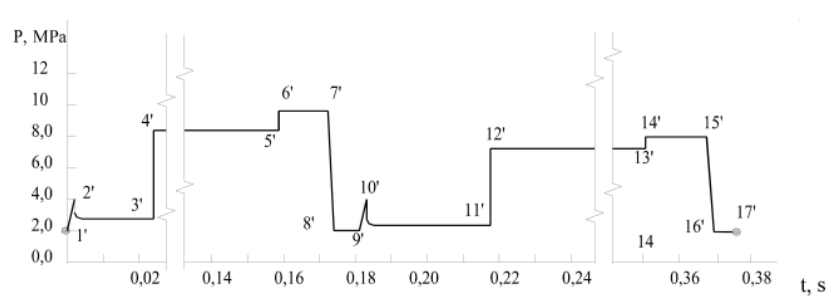

Fig. 3. Graphs of the oil pressure change during the operating cycle of the hydraulic cylinder of the mortar pump drive

As a result of analytical studies, it was decided to use a flow regulator in a hydraulic circuit in the equipment for finishing works. The flow regulator ensures constant uniform supply of oil to the hydraulic cylinder of the mortar pump drive. This makes it possible to assert that the oil consumption during the operation of the hydraulic mortar pump will be $Q_{h c}=$ const and will be

$Q_{h c}^{\max }=v_{h c \max } \cdot S=0.403 \cdot 38.50 \cdot 10^{-6} \cdot 3600=0.56 \mathrm{~m}^{3} / \mathrm{h}$,

where $v_{h c \text { max }}-$ the maximum speed of the motion of the hydraulic cylinder piston in the mortar pump;

$S$ - piston surface area of the hydraulic cylinder of the mortar pump.

Parameters $v_{h c \text { max }}$ and $S$ have been determined by research, confirmed experimentally and accepted as basic parameters for designing prototype industrial equipment samples.

The oil pressure in the hydraulic system during the operating cycle of the hydraulic cylinder has the maximum value with the piston motion in the upward direction and is $P_{h c}=9.12 \mathrm{MPa}$. The operating pressure of the oil in the system is $P_{o p}=4.22 \mathrm{MPa}$.

Hydraulic system is calculated at maximum pressure. The pump is selected according to the installed power $P_{p}$

$P_{p} \geq p^{\max } \cdot Q_{p}^{\max }$

Oil supply by the pump

$Q_{p}^{\max }=\left(Q_{h m}+Q_{h c}\right) / \eta_{v \cdot p}$.

For the hydraulic system, the oil supply is equal to

$Q_{p}^{\max }=(0.302+0.56) / 0.8=1.0775 \mathrm{~m}^{3} / h$.

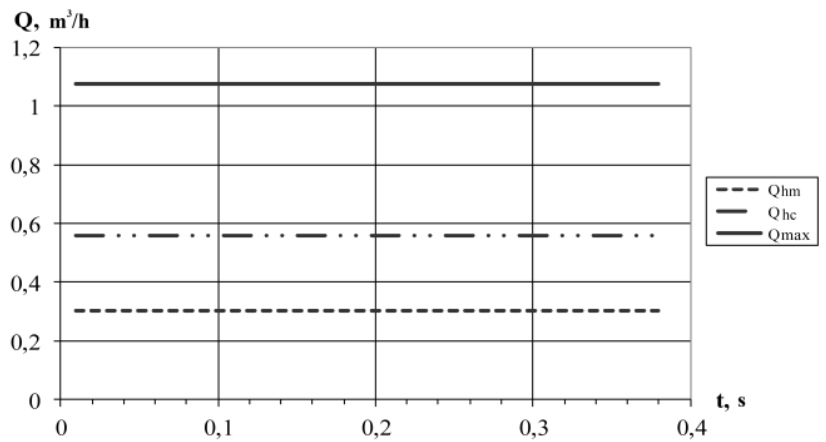

Fig. 4. Oil supply by the pump and oil consumption on the hydraulic motor of the working body drive shaft of the mixer and on the hydraulic cylinder of the mortar pump drive

The pressure in the hydraulic system $P^{\max }=9,12 \mathrm{MPa}$. The pump power is

$P_{p} \geq \frac{9,12 \cdot 10^{6} \cdot 1.0775}{60 \cdot 60}=2.73 \mathrm{~kW}$.

Various factors, such as the mobility of the mixture, the length of the pipeline, the pump flow, influence the mortar pump power. It is possible to study the complex influence of these factors on power using the method of planning a multifactorial experiment. Based on the data obtained in previous studies, we will perform this procedure.

Table 1: Variation intervals of parameters

\begin{tabular}{|c|c|c|c|c|c|c|c|}
\hline \multirow[b]{2}{*}{ No. } & \multirow[b]{2}{*}{ Name } & \multirow[b]{2}{*}{$\begin{array}{c}\text { Denoted } \\
\text { as }\end{array}$} & \multirow[b]{2}{*}{ 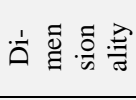 } & \multicolumn{3}{|c|}{ Level } & \multirow{2}{*}{$=\stackrel{\grave{\Xi}}{.}$} \\
\hline & & & & $\begin{array}{c}\text { low } \\
(-)\end{array}$ & $\begin{array}{c}\text { zero } \\
(0)\end{array}$ & $\begin{array}{l}\text { top } \\
(+)\end{array}$ & \\
\hline $\mathrm{X}_{1}$ & Lowability & $L$ & $\mathrm{~cm}$ & 8 & 10 & 12 & 2 \\
\hline
\end{tabular}




\begin{tabular}{|l|l|c|c|c|c|c|c|}
\hline $\mathrm{x}_{2}$ & Length & $l$ & $\mathrm{~m}$ & 50 & 100 & 150 & 50 \\
\hline $\mathrm{x}_{3}$ & Feed & $Q$ & $\mathrm{~m}^{3} / \mathrm{h}$ & 1 & 2 & 3 & 1 \\
\hline
\end{tabular}

In a general form, for the three-factor experiment [19]:

$y_{u}=b_{0}+\sum_{1}^{k} b_{i} x_{i}+\sum_{1}^{k} b_{i i} x_{i}^{2}+\sum_{1}^{k} b_{i j} x_{i} x_{j}$

where $i, j=1,2, \ldots, k$ are the ordinal numbers of factors $(i \neq j) ; y_{u}$ is the function; $\mathrm{x}_{1}, \mathrm{x}_{2}, \ldots, \mathrm{x}_{\mathrm{k}}$ are the starting factors; $\mathrm{b}_{0}, \mathrm{~b}_{1}, \mathrm{~b}_{2}, \ldots$, $b_{12}, b_{13}, \ldots, b_{i j}, b_{i i}$ are the coefficients of equation, which are calculated by the following formulas:

$b_{0}=0,1831[0 y]-0,0704 \sum_{1}^{k}[i i y]$

$b_{i}=0,1[i y]$

$b_{i i}=-0,0704[0 y]+0,5[i i y]-0,1268 \sum_{1}^{k}[i i y]$

$b_{i j}=0,125[i j y]$.

Functional dependence of the aforementioned parameters on the pumping process takes the form:

$$
\begin{aligned}
& y_{u}=b_{0}+b_{1} x_{1}+b_{2} x_{2}+b_{3} x_{3}+b_{11} x_{1}^{2}+b_{22} x_{2}^{2}+ \\
& +b_{33} x_{3}^{2}+b_{12} x_{1} x_{2}+b_{13} x_{1} x_{3}+b_{23} x_{2} x_{3}= \\
& =2,941-0,784 x_{1}+1,572 x_{2}+2,175 x_{3}- \\
& -0,029 x_{1}^{2}+0,520 x_{2}^{2}+0,955 x_{3}^{2}- \\
& -0,019 x_{1} x_{2}-0,046 x_{1} x_{3}+0,144 x_{2} x_{3} .
\end{aligned}
$$

Let us construct graphic dependencies on the expression (16).

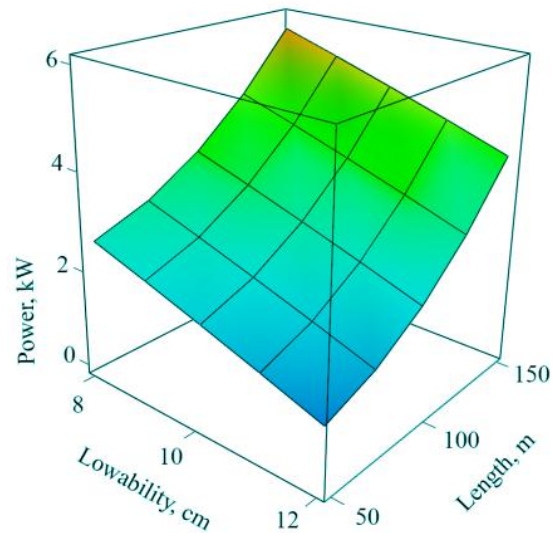

Fig. 5. Power dependence on lowability and length

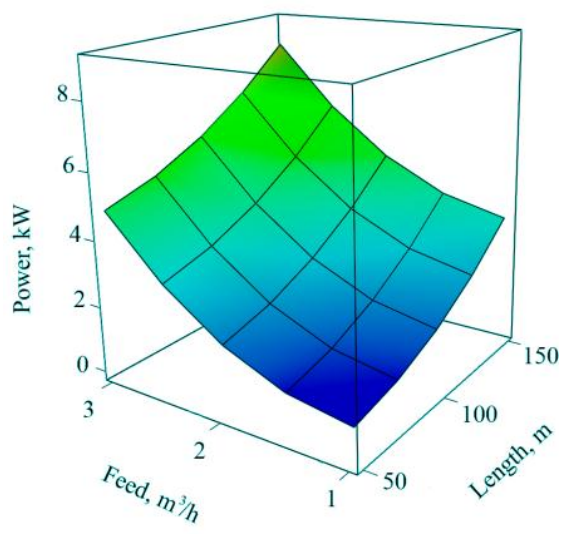

Fig. 6. Power dependence on feed and length

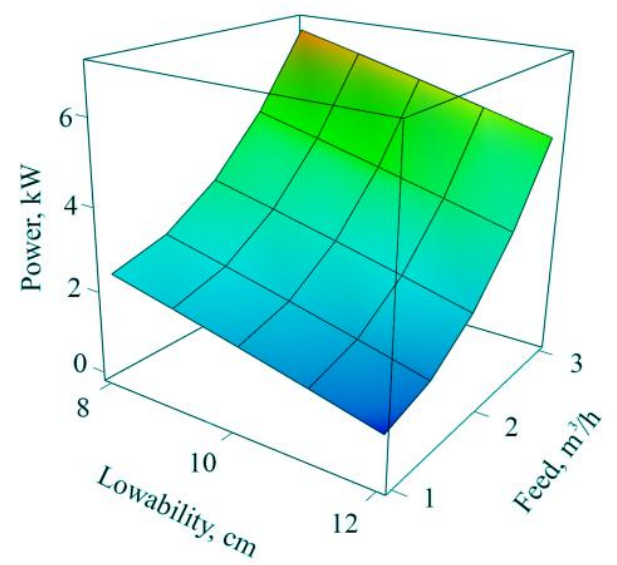

Fig. 7. Power dependence on lowability and feed

Below in fig. $8-10$ there are provided the bivariate dependences of power on the parameters listed above. This will make it possible to visualize more clearly the influence of each of the factors on the power consumption.

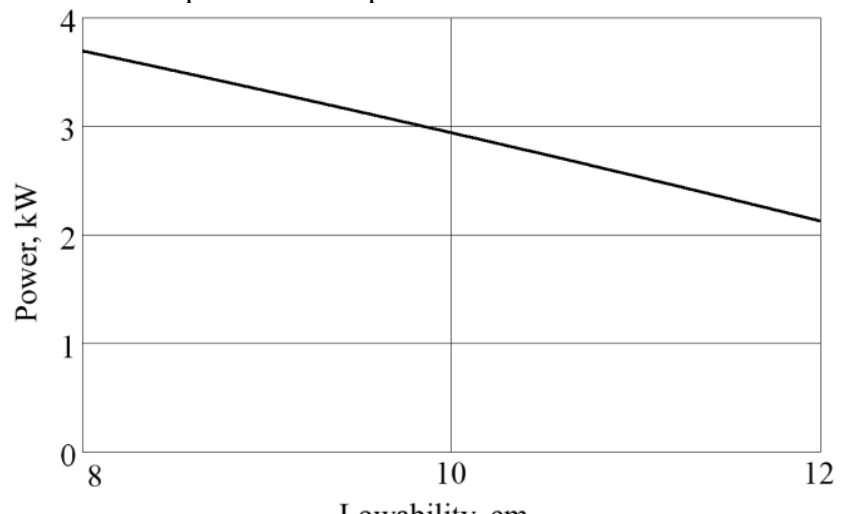

Lowability, $\mathrm{cm}$

Fig. 8. Power dependence on lowability (length $=100 \mathrm{~m}$, feed $=2 \mathrm{~m}^{3} / \mathrm{h}$ ) One can see from the graph in fig. 8, the dependence of power on mobility is inversely proportional - the greater the mobility of the mixture, the easier it is for the mortar pump to pump it.

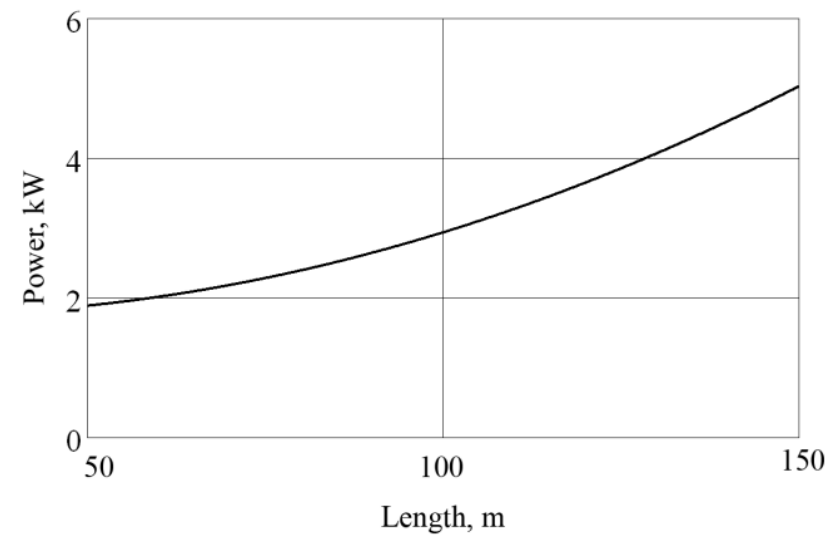

Fig. 9. Power dependence on length (lowability $=10 \mathrm{~cm}$, feed $=2 \mathrm{~m}^{3} / \mathrm{h}$ )

The length of transportation (fig. 9) more significantly affects the power consumption, since the dependence increases nonlinearly. 


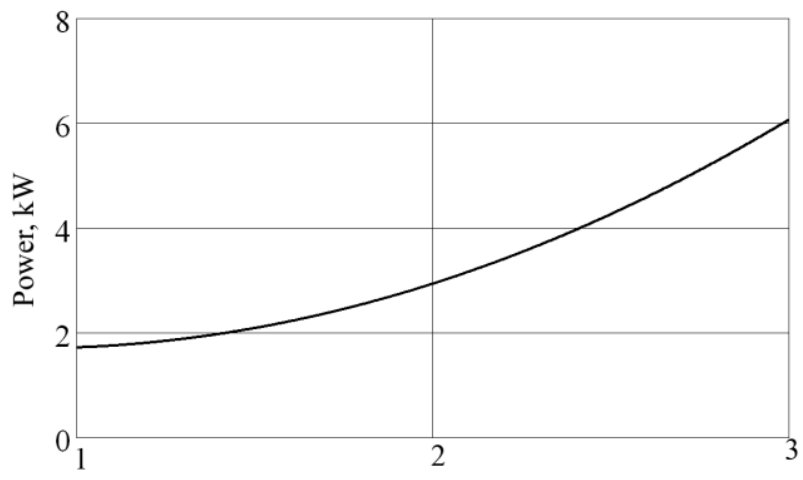

Feed, $\mathrm{m}^{3} / \mathrm{h}$

Fig. 10. Power dependence on feed (lowability $=10 \mathrm{~cm}$, length $=100 \mathrm{~m}$ )

The greatest influence on the consumed power of the mortar pump is exerted by its feeding (fig. 10) - the power difference between the minimum and maximum feed values differs thrice.

The above calculations show that, due to the use of a hydraulic drive of the main working units of the plastering machine, its energy intensity has been reduced to $11.5 \mathrm{~kW}$, and the metal content is almost twice as low as the existing analogues. The hydraulic system operates in optimal mode, which provides stable operation, as in the case of a belt-blade mixer and a hydraulic mortar pump as well.

It should be noted that, unlike plastering machines of domestic production, there almost no machines of foreign production which can allow to take the mortar from the carbody of a dumptruck.

\section{Conclusion}

Summing up all the foregoing, we can say that the use of the hydraulic drive plastering plant during the execution of works related to the use of building mortars, allows you to organize a stable mechanized high-performance process of applying the latter to the working surfaces, to reduce to a minimum the loss of solution during the work, to bring the variable production of plasterer to 35 $\mathrm{m}^{2}$. In addition, the reduction in the metal capacity and energy intensity of the equipment has been achieved by using one power and oil pump system for the drive of all the main working bodies (rotary hopper-mixer and mortar pump) of the hydraulic drive plastering station.

\section{References}

[1] Onischenko V.O. (1996). Rozrakhunok vsmoktuvalnoho kulovoho klapana rozchynonasosa. Progressivnyie tehnologii i mashinyi dlya proizvodstva stroymaterialov, izdeliy i konstruktsiy, 102 104.

[2] Hendrickx R., Roels S., Van Balen K. (2010), Measuring the water capacity and transfer properties of fresh mortar, Cement and Concrete Research, 40 (12), 1650-1655. DOI: 10.1016/j.cemconres.2010.08.002.

[3] Jacobsen S., Haugan L., Hammer T. A., Kalogiannidis E. (2009), Flow conditions of fresh mortar and concrete in different pipes. Cement and Concrete Research, 39 (11), 997 - 1006. DOI: 10.1016/j.cemconres.2009.07.005

[4] Xiao H.Y., Yue W.H. (2011), Experimental Research on Rheological Properties of Cemented Mortar in Tail Void Grouting of Shield Tunnel. Advanced Materials Research, 261 - 263, 1201 1205. DOI: 10.4028/www.scientific.net/AMR.261-263.1201.

[5] Kosky P., Balmer R., Keat W., Wise G. (2013). Chapter $10-$ Manufacturing Engineering. Exploring Engineering (Third Edition), 205 - 235. DOI: 10.1016/b978-0-12-415891-7.00010-8.

[6] Korobko B., Vasyliev Ie. (2017) Test method for rheological behavior of mortar for building work. Acta mechanica et automatica, 11/3 (41), 173 - 177. DOI: 10.1515/ama-2017-0025.

[7] Pedrajas C., Rahhal V., Talero R. (2014). Determination of characteristic rheological parameters in Portland cement pastes. Con- struction and Building Materials, 51, 484 - 491. DOI: 10.1016/j.conbuildmat.2013.10.004.

[8] Assaad J.J., Daou Y. (2014), Cementitious grouts with adapted rheological properties for injection by vacuum techniques, Cement and Concrete Research, 59, 43 - 54. DOI: 10.1016/j.cemconres.2014.01.021

[9] Wang G.L., Ma M.L., Miao D.M., Ma H.J. (2014). Pump Ability of Concrete Mixture Improvement Based on Rich Mortar Theory Testing Method. Applied Mechanics and Materials, 472, 704 - 707. DOI: 10.4028/www.scientific.net/AMM.472.704.

[10] Chen X., Wu S., Zhou J. (2013). Experimental and modeling study of dynamic mechanical properties of cement paste, mortar and concrete. Construction and Building Materials, 47, $419-430$ DOI: 10.1016/j.conbuildmat.2013.05.063.

[11] Perrot A., Rangeard D., Picandet V., Mélinge Y. (2013), Hydromechanical properties of fresh cement pastes containing polycarboxylate superplasticizer, Cement and Concrete Research, 53, 221 - 228. DOI: 10.1016/j.cemconres.2013.06.015.

[12] Korobko B. (2016), Investigation of energy consumption in the course of plastering machine's work, Eastern-European Journal of Enterprise Technologies, 4/8 (82), 4 - 11. DOI: 10.15587/17294061.2016.73336.

[13] Roussel N. (2005) Steady and transient flow behaviour of fresh cement pastes, Cement and Concrete Research, 35, $1656-1664$. DOI: 10.1016/j.cemconres.2004.08.001

[14] Onyshchenko O.H., Vaschenko K.M. (2006), Rozrakhunok potuzhnosti ta vyznachennia oporiv, shcho vynykaiut pry roboti strichkovoho shnekovoho rozchynozmishuvacha. Visnyk KDPU, 1 (36), $58-63$

[15] Navrotskiy K.L. Teoriya i praktika gidro- i pnevmoprivodov. (1991). M.: Mashinostroenie, 384.

[16] Korobko B., Zadvorkin D., Vasyliev Ie. (2017) Study of the operating element motion law for a hydraulic-driven diaphragm mortar pump, Eastern-European Journal of Enterprise Technologies, 4/7 (88), 25 - 31. DOI: 10.15587/1729-4061.2017.106873.

[17] Onyshchenko O.H., Vasyliev A.V., Ustiantsev V.U. (2002). Priamotochnyi maloimpulsnyi nasos iz kombinovanym pryvodom dvokh porshniv. Haluzeve mashynobuduvannia, budivnytstvo, 3 5.

[18] Kukoba A.T. (2000), Hidropryvidnyi rozchynonasos podviinoi dii. Dissertation, 142

[19] Letskiy E. (1977) Planirovanie eksperimenta v issledovanii tehnologicheskih protsessov. M.: Mir, 552. 